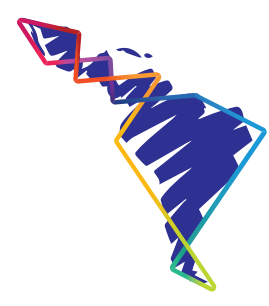

\title{
Migraciones climáticas: el papel de los derechos humanos para superar el persistente vacío jurídico*
}

\author{
Climate Migrations: The Role of \\ Human Rights to Overcome the \\ Persistent Legal Vacuum
}

\section{Migrações climáticas: o papel dos direitos humanos para superar o persistente vazio jurídico}

\author{
Beatriz Felipe Pérez ${ }^{1}$ \\ Daniel Iglesias Márquez² \\ Paola Villavicencio Calzadilla ${ }^{3}$
}

\section{Resumen}

Los impactos del cambio climático afectan, directa e indirectamente, a los patrones de movilidad humana. De hecho, existen ya ejemplos de migraciones climáticas alrededor de todo el planeta. Las migraciones climáticas transfronterizas son especialmente relevantes, pues uno de los problemas más graves a los que se enfrentan las personas que huyen de sus países a causa del cambio climático, junto con otros motivos, es el escaso reconocimiento de su situación por el derecho internacional y, en consecuencia, la falta de protección jurídica. Ante este vacío, en el presente artículo se analiza la posible aplicación del derecho internacional de los

* La presente obra se ha elaborado en el marco del PROYECTO DE I+D: "La constitución climática global: gobernanza y Derecho en un contexto complejo" (CONCLIMA-DER2016-80011-P), (MINECO/FEDER, UE), Programa Estatal de Fomento de la Investigación Científica y Técnica de Excelencia, subprograma Estatal de Generación del Conocimiento, en el marco del Plan Estatal de Investigación Científica y Técnica y de Innovación 2013-2016, efectuada por resolución de 17 de junio de 2015 (BOE de 23 de junio) de la Secretaría de Estado de Investigación, Desarrollo e Innovación (SEIDI), Ministerio de Economía y Competitividad.

1 Investigadora asociada al Centro de Estudios de Derecho Ambiental de Tarragona (CEDAT), de la Universitat Rovira i Virgili (España).

2 Investigador postdoctoral Juan de la Cierva de la Universidad de Sevilla e investigador asociado al Centro de Estudios de Derecho Ambiental de Tarragona de la Universitat Rovira i Virgili.

3 Investigadora postdoctoral, Faculty of Law, North-West University (Sudáfrica) e investigadora invitada, Faculty of Law, University of Groningen (Países Bajos). 
derechos humanos, mediante dos formas, por un lado, como garantía básica de los derechos fundamentales de estas personas y, por otro, como fundamento para exigir la responsabilidad internacional de los Estados contaminantes, ante las violaciones de los derechos humanos que experimentan los migrantes climáticos.

Palabras clave: migraciones climáticas, derechos humanos, cambio climático, responsabilidad internacional de los Estados

\section{Summary}

The impacts of climate change affect, directly and indirectly, patterns of human mobility. In fact, there are already examples of so-called climatic migrations around the entire planet. Cross-border climate migrations are especially relevant, as one of the most serious problems faced by people fleeing their countries due to climate change, along with other reasons, is the limited recognition of their situation by international law and, consequently, the lack of legal protection. Given this gap, the current article analyzes the possible application of international human rights law, in two ways, on the one hand, as a basic guarantee of the fundamental rights of these people and, on the other, as a basis for demanding responsibility of pollutant States, in face of the human rights violations experienced by climate migrants.

Keywords: Climatic migrations, Human rights,; Climate change, International responsibility of States

\section{Resumo}

Os impactos das mudanças climáticas afetam, direta e indiretamente, aos padrões de mobilidade humana. De fato, já existem exemplos de migrações climáticas ao redor de todo o planeta. As migrações climáticas transfronteiriças são especialmente relevantes, já que um dos problemas mais sérios enfrentados pelas pessoas que fogem de seus países devido às mudanças climáticas, juntamente com outras razões, é o limitado reconhecimento de sua situação pelo direito internacional e consequentemente, a falta de proteção jurídica. Perante este vazio, no presente artigo se analisa a possível aplicação do direito internacional dos direitos humanos, de duas formas, de um lado, como garantia básica dos direitos fundamentais dessas pessoas e, de outro, como fundamento para exigir a responsabilidade dos Estados poluentes, em face das violações dos direitos humanos que experimentam os migrantes climáticos.

Palavras-chave: Migrações climáticas, Direitos humanos, Mudanças climáticas,; Responsabilidade internacional dos Estados 


\section{INTRODUCCIÓN}

Las migraciones climáticas ${ }^{4}$ representan uno de los mayores, aunque menos comprendido, desafíos del siglo XXI. En los últimos años, aproximadamente 22,5 millones de personas han sido desplazadas cada año por desastres meteorológicos o relacionados con el clima, lo que equivale a unas 62000 personas al día (IDMC, 2015). Según el Centro de Monitoreo de los Desplazamientos Internos (IDMC, por sus siglas en inglés), en el 2016 hubo 24,2 millones de nuevos desplazamientos, debidos a desastres (IDMC, 2017), mientras que en el 2017 hubo 18,8 millones (IDMC, 2018). Estas cifras, que no incluyen los movimientos migratorios internacionales, reflejan la realidad y magnitud de las migraciones climáticas, las cuales, en última instancia, son la conjunción de otras crisis no superadas y tienen sus verdaderas raíces en los persistentes modelos de desarrollo insostenibles generadores de desigualdades e injusticias.

A pesar de estos datos alarmantes y de que ya hace más de 40 años que se publicaron los primeros informes al respecto (Brown, 1976), el conocimiento que se tiene de las migraciones climáticas sigue siendo limitado. En la actualidad, siguen existiendo fuertes debates en torno a diferentes aspectos, entre ellos: las cifras (Gemenne, 2011), la denominación (Dun y Gemenne, 2008) y la protección jurídica de las personas que migran por causa del cambio climático, especialmente de aquellas que lo hacen fuera de sus países, pues se enfrentan a un persistente legal gap o vacío jurídico que aumenta su vulnerabilidad (Türk y Dowd, 2014).

En este sentido, en los últimos años se han venido desarrollando diferentes propuestas para superar dicho vacío jurídico 5 . Así, junto a la abundante doctrina que invita a la adaptación de los instrumentos existentes en el derecho internacional para dar cabida a la protección de los derechos de quienes migran por motivos climáticos (Cooper, 1998), también se han desarrollado varias propuestas de tratado internacional ad hoc (Hodkinson, 2011; Prieur, 2011) o de un Protocolo a la Convención Marco de las Naciones Unidas sobre el Cambio Climático (CMNUCC), de 1992 (Biermann y Boas, 2008; Gogarty, 2011). Igualmente, se han promovido otras alternativas para favorecer la protección de los migrantes

4 Se emplea el término "migración climática" para designar al movimiento de personas causado, directa e indirectamente, por la degradación ambiental que genera el cambio climático. La Organización Internacional para las Migraciones (OIM) define a los migrantes ambientales como: “(...) personas o grupos de personas que, principalmente en razón de un cambio repentino o progresivo en el medio ambiente, que incide adversamente en sus vidas o en las condiciones de vida, se ven obligados a abandonar el lugar habitual de residencia, u optan por hacerlo, ya sea temporalmente o con carácter permanente, y que se desplazan dentro del país o al extranjero" (OIM, 2014, p. 15).

5 Para conocer algunas de las propuestas actuales, véanse Behrman y Kent (2018). 
climáticos con diferentes grados de aceptación, como los Principios de Península (Displacement Solutions, 2013) o la Iniciativa Nansen (Nansen Initiative, 2015).

En esta línea, la comunidad internacional ha comenzado a prestar cierta atención a las relaciones entre el cambio climático y las migraciones. Entre estos avances cabe destacar: la puesta en marcha de la "Task Force on Displacement" creada tras la 21. aㅡ reunión de la Conferencia de las Partes de la CMNUCC (COP21) (CMNUCC, 2017); los avances de la "Platform on Disaster Displacement", que surgió de la Iniciativa Nansen (PDD, s. f.); la adopción de la Declaración de Nueva York para los Refugiados y los Migrantes (ONU, 2016), en la que se reconoce el medio ambiente y el cambio climático como factores que impulsan los movimientos migratorios, destacando también que en la preparación del Pacto Mundial para una Migración Segura, Regular y Ordenada ${ }^{6}$ se incluyeron consultas específicas sobre migración y medio ambiente; la admisión de la Agenda de Desarrollo Sostenible 2030 (ONU, 2015), que incluye a las personas migrantes en sus 17 objetivos y, por primera vez, incorpora la migración en la agenda global de desarrollo; y, finalmente, la adquisición de las Directrices para la Protección de los Migrantes en Países Afectados por Conflictos o Desastres Naturales en el 2016 (MICIC, 2016).

Sin embargo, a pesar de la importancia de estos avances, la mayoría de los Gobiernos e instituciones internacionales sigue sin abordar el problema de la forma necesaria y las respuestas para solventar el vacío jurídico continúan siendo insuficientes. Se puede afirmar que, hasta ahora, el derecho internacional ha permanecido ajeno a la realidad de las migraciones climáticas y, en la actualidad, la situación de quienes se trasladan por motivos climáticos sigue sin estar competentemente contemplada.

Lo cierto es que la adaptación o la interpretación más extensiva de los instrumentos jurídicos existentes requiere de mucha voluntad política y, aunque sea posible, a corto plazo parece ciertamente una meta difícil de alcanzar (Felipe, 2016; Felipe, 2018). En este contexto, el marco jurídico internacional de los derechos humanos, aplicables a cualquier persona, independientemente de su condición jurídica, se configura como una herramienta fundamental para la protección de los migrantes climáticos. Este mismo marco requiere que los Estados (de origen y receptores) aseguren el ejercicio y protección de los derechos humanos de las personas migrantes, con independencia de su situación migratoria.

Con el objetivo de avanzar en la protección jurídica de quienes migran por motivos climáticos, en este artículo se analiza, en primer lugar, la relación entre

6 La Declaración de Nueva York inició un proceso de consulta y negociación intergubernamental para la adopción de este pacto mundial que se espera sea adoptado en el 2018. Para mayor información sobre el proceso de negociación y los propósitos de este, véase www.iom.int/global-compact-migration. 
cambio climático, derechos humanos y migraciones. A continuación, se realiza un estudio de la evolución del régimen internacional del cambio climático y del marco jurídico internacional de las migraciones, en relación con las climáticas, con el fin de identificar las situaciones de desprotección jurídica. En el siguiente apartado, se explora, por un lado, la aplicación del marco internacional de los derechos humanos como herramienta para la protección de estas personas y, por otro, se estudia la posibilidad de responsabilizar a los Estados contaminantes por la vulneración de los derechos humanos de los migrantes climáticos. Finalmente, se concluye que el derecho internacional de los derechos humanos constituye una herramienta fundamental para superar el vacío jurídico en el que se encuentran los migrantes climáticos, especialmente cuando cruzan fronteras internacionales.

\section{LA RELACIÓN ENTRE EL CAMBIO CLIMÁTICO, LOS DERECHOS HUMANOS Y LAS MIGRACIONES}

El quinto informe del Panel Intergubernamental de Expertos sobre el Cambio Climático (IPCC) confirma que el cambio climático es inequívoco y que sus principales causas son las emisiones de gases de efecto invernadero (GEI) de origen antropogénico. Se identifican como impactos relacionados con tal cambio climático el incremento en la frecuencia de eventos meteorológicos extremos y de desastres, la elevación del nivel del mar, las inundaciones, las olas de calor, las sequías, la desertificación, el mayor estrés hídrico y el aumento en la difusión de enfermedades transmitidas por vectores como malaria o dengue, etc. (IPCC, 2014).

Estos impactos afectan la calidad de vida de muchas personas, especialmente en las regiones más vulnerables del planeta, que son, entre otras, el cuerno de África, el Sahel, América Central e India, junto con algunas partes del norte de América, como Alaska y los pequeños Estados insulares de escasa elevación, más que todo en el Caribe y el Pacífico (Sherbinin, 2014; Hamza, Koch, Plewa, 2017). Esto constituye una gran injusticia, pues dichas regiones son las que históricamente han contribuido en menor medida a las emisiones de GEI (Jamieson, 2011).

Además, los impactos climáticos amenazan directa e indirectamente el pleno disfrute de los derechos humanos (Godínez, 2006; Sarshar, 2011), como el propio Alto Comisionado de las Naciones Unidas para los Derechos Humanos (ACNUDH) ha reconocido en numerosas ocasiones? ${ }^{7}$. Derechos de tanta importancia como el referido a la vida se ven afectados por el incremento de huracanes e inundaciones, así como por el aumento del hambre, la malnutrición y las enfermedades infecciosas agravadas por el cambio climático (ACNUDH, 2009). De hecho, entre los años

7 Resoluciones del Consejo de Derechos Humanos de la ONU sobre Derechos Humanos y Cambio Climático 7/23 (2008), 10/4 (2009), 18/22 (2011), 26/27 (2014), 29/15 (2015) y 32/33 (2016). 
2030 y 2050, los efectos del cambio climático podrían ocasionar, aproximadamente, 250000 muertes adicionales al año (Hales et al., 2014).

De igual forma, el derecho a una alimentación adecuada, así como el derecho humano al agua se ven afectados. Al tener fuertes repercusiones negativas para el ámbitoagrícola y otros sectores productivos, los impactos del cambio climático agravan las crisis alimentarias, además de afectar la distribución del agua en el mundo, dejando a muchas personas que ya padecen estrés hídrico en situaciones aún más peligrosas (IPCC, 2014; OXFAM, 2009). Por ejemplo, se estima que antes de que el nivel del mar supere e inunde totalmente las islas y atolones del Pacífico y el Índico, como Tuvalu, las Maldivas o Kiribati, el cambio climático destruirá las posibilidades de tener una vida saludable a causa de la intrusión del agua marina en los acuíferos de agua dulce, inundaciones y tormentas (Storlazzi et al., 2018).

El cambio climático también conlleva efectos adversos para la salud de millones de personas, teniendo impactos diferenciados para las mujeres y otros grupos de población como los enfermos y la niñez (Duong, 2010; OMS, 2012; OMS, 2016). Por su parte, las comunidades indígenas son especialmente vulnerables, ya que su mera existencia está a menudo inextricablemente unida al medio ambiente en el que habitan, por lo que derechos como la libre determinación o la expresión cultural se ven amenazados por los impactos del cambio climático (Acevedo, 2014; Duong, 2010).

En virtud de ello, en su informe de 2016, el Profesor John Knox, exrelator especial sobre la cuestión de las obligaciones de derechos humanos, relacionadas con el disfrute de un medio ambiente sin riesgos, limpio, saludable y sostenible, no solo resaltó la creciente atención al vínculo entre el cambio climático y los derechos humanos, sino que determinó que los efectos negativos previsibles del cambio climático en el disfrute de los derechos humanos entrañan, para los Estados, la obligación de adoptar medidas destinadas a protegerlos (CDH, 2016).

Las migraciones climáticas constituyen una de las consecuencias de las condiciones ambientales degradadas por los efectos del cambio climático en entornos socioeconómicos vulnerables, en los que la transgresión de los derechos humanos es evidente (Fatima, Jawadurovna y Coelho, 2014). Deben entenderse como un fenómeno que no depende solo de las características de la modificación ambiental que las genera, sino también de las condiciones socioeconómicas de la población afectada, de su capacidad de adaptación y de las características concretas del lugar en cada caso; es decir, se trata de un fenómeno complejo y multicausal. Muchas personas migran bien como una forma de anticiparse a peores condiciones ambientales, o bien como estrategia de supervivencia (The Government Office for 
Science, 2011). Asimismo, aunque se trata de un fenómeno heterogéneo, las migraciones climáticas presentan una serie de particularidades comunes que definen su realidad: siempre que la situación lo permita, tienden a ser movimientos de población temporales, dentro de los Estados y de carácter forzado (Felipe, 2016).

En la actualidad, hay ejemplos concretos de migraciones climáticas alrededor de todo el planeta, desde las islas de escasa altura en el océano Pacífico, que se enfrentan a la escasez de agua dulce debida a la elevación del nivel del mar y a las tormentas cada vez más frecuentes (ACNUDH, 2009; Barnett, 2001), hasta algunas comunidades en Alaska, como Shishmaref y Kivalina, que han de reubicarse, debido a que el permafrost sobre el que se asentaban sus casas se está derritiendo (Bronen, 2010; Felipe y Salles, 2015). Países como Bangladesh no se ven afectados solo por la elevación del mar, sino por inundaciones cada vez más intensas y frecuentes que incrementan los movimientos migratorios, primordialmente hacia las grandes urbes (Pender, 2008; Rezaul, 2017). En el delta del río Mekong (una de las áreas más vulnerables a la degradación ambiental y a las consecuencias del cambio climático mundial) la erosión de la tierra, las sequías, los ciclones, las inundaciones y la salinización han sido señaladas como factores que impulsan la migración de un alto número de personas (Entzinger y Scholten, 2016). Asimismo, las sequías que afectaron Angola en el 2013 y las posteriores inundaciones generaron importantes migraciones en el país (OIM, 2014).

En Centroamérica y México, factores ambientales como la desertificación, las sequías y otros eventos extremos contribuyen a los complejos patrones de movilidad en esta región (Warner, Sherbinin y Chai-Onn, 2009). En Panamá, por ejemplo, los habitantes de una de las islas de la comunidad indígena Kuna-Yala, en el mar Caribe, se encuentran llevando a cabo tareas de reasentamiento, tras tomar la decisión de abandonar el archipiélago y reubicarse en el continente, debido a que la sobrepoblación, la escasez de agua potable y la cada vez menor proporción de terreno disponible están dificultando su supervivencia y el disfrute de sus derechos humanos (Displacement Solutions, 2016). Así, los movimientos migratorios en la región podrían incrementarse, en la medida en que los efectos del cambio climático se intensifiquen.

En América del Sur, tanto los eventos extremos como los de desarrollo lento están generando movimientos poblacionales en Brasil, fundamentalmente en el nivel interno (Pires, Lyra, Salles y Abreu, 2016). En Chile, un caso que llama mucho la atención es el de la comuna de Monte Patria en la Provincia del Limarí, donde la escasez de agua ha afectado la economía de su población, altamente dependiente de la agricultura, y ha provocado la migración de un gran número de personas en busca de empleo (Priotto, 2017). Una situación similar se vive en Bolivia, donde 
la desaparición del segundo lago más grande del país, el Lago Poopó, a causa del cambio climático, entre otros, ha ocasionado la migración de integrantes de una comunidad indígena aledaña, cuyos medios de subsistencia y derechos se han visto amenazados (Clark, 2016). También resulta interesante señalar una de las conclusiones más relevantes del informe "Migraciones, ambiente y cambio climático. Estudios de Caso en América del Sur", publicado por la Organización Internacional de las Migraciones (OIM) en el 2017. En este, se analizaron casos concretos como el mencionado de Chile, junto con Argentina, Brasil, Colombia y Ecuador. La conclusión fue que "(...) en todos los casos se producen movimientos migratorios de tipo permanentes y transitorios por causas de la intensificación de eventos climáticos extremos provocados por el cambio climático" (Priotto, 2017, p. 142).

Estos son solo algunos de los muchos ejemplos de migraciones relacionadas con el cambio climático, que están teniendo lugar en la actualidad en diversas regiones del mundo. Todos ellos demuestran que las comunidades más desfavorecidas en los países empobrecidos son las que sufren en mayor medida las consecuencias del cambio climático y dónde las migraciones climáticas son más evidentes hoy en día. Si bien el cambio climático supone una amenaza para el pleno disfrute de los derechos humanos de las personas afectadas por este, como se mencionaba, en el caso particular de quienes migran por motivos climáticos esta amenaza es incluso mayor (IASC, 2008; Godínez, 2006; Sarshar, 2011; Solà, 2012).

\section{LA (DES)PROTECCIÓN DE LOS MIGRANTES CLIMÁTICOS}

A pesar de los recientes avances políticos y de la evidencia empírica cada vez más clara, ni el marco jurídico internacional del cambio climático ni el derecho internacional de las migraciones se han adaptado a la realidad de las migraciones climáticas. Así, como se describe en los siguientes apartados, ambos regímenes continúan sin incluir, de manera explícita o suficiente, la situación de quienes se trasladan por motivos climáticos ni proporcionan mecanismos efectivos para su protección.

\subsection{La lenta evolución del marco jurídico internacional del cambio climático ante las migraciones climáticas}

En 1992, durante la conocida Cumbre de la Tierra celebrada en Río de Janeiro, se adoptó la CMNUCC (ONU, 1992). Mediante la CMNUCC, las partes firmantes se comprometieron a conseguir "(...) la estabilización de las concentraciones de gases de efecto invernadero en la atmósfera a un nivel que impida interferencias antropógenas peligrosas en el sistema climático" (artículo 2). El texto de la CMNUCC no hace mención de la protección jurídica de las personas que migran por motivos climáticos. De hecho, al ser un tratado internacional multilateral de 
protección ambiental, la CMNUCC concierne más bien a las relaciones entre Estados, por lo que no entra en la discusión sobre los derechos que aquellos deben asegurar a los individuos o comunidades (Pires, 2013). No obstante, comprende algunos de los principios del derecho internacional del medio ambiente, esenciales para el caso de las migraciones inducidas por el cambio climático, como el principio de precaución, el de prevención, el de equidad intra- e intergeneracional y el de desarrollo sostenible.

Un primer avance significativo en el ámbito de las migraciones climáticas tuvo lugar en la COP 16, celebrada en Cancún en el 2010, con la adopción de los denominados "Acuerdos de Cancún" (CMNUCC, 2010). Gracias a los esfuerzos de ciertos Estados y actores no estatales, esta fue la primera vez que el vínculo entre las migraciones y el cambio climático apareció en un documento oficial de la Convención. Así, el párrafo 14, apartado f, invitó a las partes a intensificar su labor de adaptación, mediante

[1]a adopción de medidas para mejorar el entendimiento, la coordinación y la cooperación en lo que respecta al desplazamiento, la migración y el traslado planificado como consecuencia del cambio climático, cuando corresponda, a nivel nacional, regional e internacional.

Luego de años de negociación, los esfuerzos por la incorporación de las migraciones climáticas en el régimen jurídico del cambio climático conseguirían un avance importante en la COP 21, celebrada en París en el 2015, donde se adoptó el Acuerdo de París (CMNUCC, 2015). Este define un plan de acción global, cuya finalidad es evitar los efectos más graves del cambio climático, limitando el calentamiento global a menos de $2{ }^{\circ} \mathrm{C}$, esperando restringir el aumento a $1.5^{\circ} \mathrm{C}$ (artículo 2). El Acuerdo, que entró en vigor en noviembre de 2016, supuso un notable paso, ya que incorporó, por primera vez en un instrumento legal de alcance universal en la materia, referencias sobre las migraciones inducidas por el cambio climático. En concreto, el preámbulo del Acuerdo señala

Reconociendo también que el cambio climático es un problema común de la humanidad, por lo que las Partes, al adoptar medidas para hacer frente al cambio climático, deberían respetar, promover y tomar en consideración sus respectivas obligaciones con respecto a los derechos humanos, el derecho a la salud, los derechos de los pueblos indígenas, las comunidades locales, los migrantes, los niños, las personas con discapacidad y las personas en situaciones de vulnerabilidad y el derecho al desarrollo, así como la igualdad de género, el empoderamiento de la mujer y la equidad intergeneracional. (CMNUCC, 2015, párr. 11) 
Además, una referencia al desplazamiento relacionado con los efectos adversos del cambio climático fue integrada en el texto de la decisión del Acuerdo, concretamente, en el mecanismo de "pérdidas y daños" (CMNUCC, 2015):

Pide también al Comité Ejecutivo del Mecanismo Internacional de Varsovia que, de conformidad con sus procedimientos y su mandato, establezca un equipo de tareas que sea un complemento a los órganos y grupos de expertos existentes en el marco de la Convención, incluidos el Comité de Adaptación y el Grupo de Expertos para los Países Menos Adelantados, así como a las organizaciones y demás expertos competentes que operan al margen de la Convención, aproveche sus trabajos y recabe su participación, según el caso, con el fin de elaborar recomendaciones sobre enfoques integrados que permitan evitar, reducir al mínimo y afrontar los desplazamientos relacionados con los efectos adversos del cambio climático. (párr. 50)

A pesar de esta inclusión, en el texto se dejó claro que no habrá ningún tipo de responsabilidad jurídica o indemnización relacionada con los migrantes climáticos.

Así, aunque las migraciones climáticas no se encuentran incorporadas propiamente en el texto del Acuerdo de París, al menos se recogen en su preámbulo y en las decisiones para hacerlo efectivo. Si bien dicha inclusión se ha considerado un aspecto positivo, lo cierto es que todavía resulta insuficiente en cuanto a la gravedad y magnitud de las migraciones climáticas (UK Climate Change and Migration Coalition, 2015).

Sin embargo, aunque se evidencia su falta de ambición, al menos ahora existe un pacto de alcance mundial en el que los Estados parte se comprometen a tratar el asunto de las migraciones climáticas y, además, sirvió para crear la "Task Force on Displacement" aludida.

\subsection{Los vacíos jurídicos en el derecho internacional de los movimientos migratorios}

El derecho internacional de las migraciones incluye los marcos jurídicos que contemplan tanto los movimientos migratorios relativamente voluntarios ${ }^{9}$ forzados, como los que tienen lugar dentro de los Estados o cruzando fronteras internacionales.

8 La inclusión de este párrafo no estuvo clara hasta el final de las negociaciones y fue el resultado de los esfuerzos del lobby impulsado por el "Advisory Group on Climate Change and Human Mobility".

9 Como explican Celis y Aierdi (2015), a la hora de migrar, normalmente la toma de decisiones de las personas no ocurre de una manera totalmente libre, sino que se encuentra condicionada por unas estructuras sociales que determinan el momento y el lugar; es decir, la mayoría de los movimientos migratorios se encuentran "condicionados", en sus propias palabras: “(...) tras toda emigración, incluso en las migraciones deseadas, hay un campo de fuerzas que las motiva, campo más o menos involuntario. En términos lógicos, desde esta perspectiva, toda migración es una migración forzada, porque hay alguna fuerza, causa o resorte que la precipita" (pp. 17-18). 
En cuanto a los considerados movimientos migratorios voluntarios, en el nivel internacional, la Convención Internacional sobre la Protección de los Derechos de todos los Trabajadores Migratorios y de sus Familiares (ONU, 1990), que fue adoptada en 1990 y entró en vigor el 1 de julio de 2003, reconoce expresamente los derechos humanos de todos los trabajadores migrantes, así como los de sus familias, con independencia de su condición jurídica en el país de acogida. Sin embargo, a pesar de que pueda ser aplicada para algunos migrantes climáticos, solo lo será para quienes encajen en lo definido por la Convención. Además, dicho instrumento ha sido ratificado por muy pocos Estados, siendo estos, principalmente, países de origen de las personas migrantes (como Filipinas, Marruecos, Colombia y México), mientras que ningún país predominante de acogida lo ha hecho (UNESCO 2005; ACNUDH, 2018).

En cuanto a los movimientos forzados de población que tienen lugar dentro de los Estados, los Principios Rectores de los Desplazamientos Internos (ONU, 1998) podrían suponer el instrumento clave, pues incluyen, de manera expresa, la protección de las personas desplazadas a causa de desastres naturales o provocados por el ser humano ${ }^{10}$. No obstante, se trata de un instrumento voluntario que los Estados pueden incorporar o no en sus ordenamientos internos y que no integra ningún mecanismo de supervisión y presentación de informes. Además, aunque han sido reconocidos como un importante marco legal para la protección de personas desplazadas dentro de los países (AGNU, 2005), estos principios rectores no se podrían aplicar para las migraciones climáticas internacionales.

En el nivel regional, cabe destacar la Convención de la Unión Africana para la Protección y la Asistencia de los Desplazados Internos en África, conocida como "Convención de Kampala", que contempla expresamente el cambio climático como causa de los desplazamientos internos (OUA, 2009). Así, el artículo 5.4 de la Convención llama a los Estados parte a la adopción de medidas "para proteger y ayudar a las personas que han sido desplazadas internamente debido a los desastres naturales o producidos por el ser humano, incluyendo el cambio climático". Se ha de reconocer la importancia de este instrumento al considerarse el primer tratado internacional vinculante sobre desplazamiento interno, que protege los derechos humanos de las personas migrantes por factores climáticos. Sin embargo, no incluye la situación de aquellas que cruzan fronteras internacionales e, igualmente, el alcance de su aplicación es regional.

10 Según los Principios Rectores, el desplazamiento se produce cuando las "personas o grupos de personas [...] se han visto forzadas u obligadas a escapar o huir de su hogar o de su lugar de residencia habitual, en particular como resultado o para evitar los efectos de un conflicto armado, de situaciones de violencia generalizada, de violaciones de los derechos humanos o de catástrofes naturales o provocadas por el ser humano" (artículo 2). 
En relación con los movimientos migratorios internacionales de carácter forzado, se ha propuesto que se proteja a quienes se movilizan por motivos climáticos, mediante la Convención sobre el Estatuto de los Refugiados de 1951 y su Protocolo de 1967 (en adelante, Convención de Ginebra) (ONU, 1951, 1967). Empero, estos instrumentos no fueron creados para la protección de estas personas y presentan varias limitaciones. Entre ellas destaca, en primer lugar, el concepto jurídico de refugiado ${ }^{11}$ que, según la citada Convención de Ginebra, no contempla las causas ambientales entre los motivos para que sea concedido el estatuto de refugiado. Además, resulta complicado que se entienda al cambio climático como agente persecutor o que la degradación ambiental pueda constituir un motivo de persecución en su sentido jurídico.

En segundo lugar, otra de las limitaciones se refiere a la negativa de varios gobiernos y del Alto Comisionado de las Naciones Unidas para los Refugiados (ACNUR) por aplicar dichos instrumentos a las migraciones climáticas (ACNUR, 2008; Biermann y Boas, 2010a; Castillo, 2011; Horne, 2006). Varios casos en Australia y en Nueva Zelanda, en los que ciudadanos de Kiribati y Tuvalu han solicitado el estatuto de refugiados por motivos climáticos y han sido denegados, confirman la no adecuación actual de la Convención de Ginebra para los migrantes climáticos ${ }^{12}$. De igual modo, sería aplicable solo a las migraciones climáticas internacionales, dejando de lado a quienes se movilizan dentro de sus países.

Regionalmente, la Convención de la Organización de la Unión Africana sobre los Refugiados de 1969 (OUA, 1969) y la Declaración de Cartagena sobre los Refugiados de 1984 (ONU, 1984) ofrecen una definición más amplia que la Convención de Ginebra, incluyendo, entre las causas, las situaciones que han alterado gravemente el orden público ${ }^{13}$. Bajo ciertas interpretaciones, esto podría equipararse a la degradación ambiental fruto del cambio climático, como sequías

11 Según el artículo 1 de la Convención, un "refugiado" es una persona que "(...) debido a fundados temores de ser perseguida por motivos de raza, religión, nacionalidad, pertenencia a determinado grupo social u opiniones políticas, se encuentre fuera del país de su nacionalidad y no pueda o, a causa de dichos temores, no quiera acogerse a la protección de tal país; o que, careciendo de nacionalidad y hallándose, a consecuencia de tales acontecimientos, fuera del país donde antes tuviera su residencia habitual, no pueda o, a causa de dichos temores, no quiera regresar a él" (ONU, 1951, 1967).

12 Véase, por ejemplo: Apelación de Refugiados 72189/2000, Autoridad de Apelaciones del Estatuto de Refugiados de Nueva Zelanda, 17 de agosto de 2000, párrafo 13; 0907346 [2009] RRTA 1168 (10 de diciembre de 2009) párrafo 51 (Tribunal de Revisión de Refugiados de Australia).

13 La Convención de la OUA añade a la definición de persona refugiada que establece Ginebra que se otorgará el estatuto de personas refugiadas a las obligadas a salir de su país de origen "(...) a causa de una agresión exterior, una ocupación o una dominación extranjera, o de acontecimientos que perturben gravemente el orden público" (OUA, 1969). Y la Declaración de Cartagena también aplica la condición de refugiadas a aquellas cuyas "(...) vida, seguridad o libertad han sido amenazadas por la violencia generalizada, la agresión extranjera, los conflictos internos, la violación masiva de derechos humanos u otras circunstancias que hayan perturbado gravemente el orden público" (ONU, 1984). 
duraderas que generan hambrunas. De hecho, la Convención de la Organización de la Unión Africana ya se aplicó en el 2010-2012, cuando la sequía que afectó gravemente a Somalia hizo que muchas personas solicitaran asilo en los países vecinos (Nansen Initiative, 2014). Por el momento, los principales inconvenientes para ampliar esta protección a todos los migrantes climáticos son que se trata de instrumentos de carácter regional, no universal y que no recogen específicamente los motivos ambientales. Además, la Declaración de Cartagena es un instrumento jurídicamente no vinculante.

Finalmente, para el caso de los pequeños Estados insulares de escasa elevación, se ha de considerar que la elevación del nivel del mar trae como consecuencia la salinización de los acuíferos y la pérdida de territorio, junto con los efectos de tormentas cada vez más frecuentes e intensas, por lo que pueden resultar inhabitables en el corto plazo e incluso verse sumergidos en el largo plazo (Burkett, 2011). Esto plantea un sinnúmero de cuestiones nunca tratadas en el derecho internacional, pues no se había dado la situación de estar ante una posible "inhabitabilidad total" o "desaparición del Estado" por la elevación del nivel del mar (Gagain, 2012). Esto ha sacado a la luz la idea, aún no resuelta, de que los habitantes de estas pequeñas islas puedan llegar a ser considerados apátridas y si, por tanto, podría aplicarse la Convención sobre el Estatuto de los Apátridas (ONU, 1954). Independientemente de si se podrá suponer a estas personas apátridas o no, la probabilidad de generar el fenómeno de la apatridia de facto aumenta conforme se intensifican los efectos del cambio climático, por lo que resulta de suma importancia la aplicación de los principios establecidos en la Convención para Reducir los Casos de Apatridia (ONU, 1961).

\section{EXPLORANDO LA APLICACIÓN DEL MARCO INTERNACIONAL DE LOS DERECHOS HUMANOS A LAS MIGRACIONES CLIMÁTICAS}

\subsection{Los derechos humanos como garantía mínima de protección}

Los instrumentos internacionales en materia de derechos humanos proporcionan cierta protección a quienes migran (dentro y fuera de sus países) por múltiples razones, asegurando el resguardo de sus derechos fundamentales y la asistencia de los Estados, de conformidad con sus obligaciones de derechos humanos. En este contexto, aunque todavía se necesita una aplicación más concreta de esas normas a las migraciones climáticas a fin de superar los vacíos que aún existen y prestar atención a la vulnerabilidad de las personas que se encuentran en esa situación particular (CDH, 2012), el marco internacional de los derechos humanos se presenta como una opción, con el fin de ofrecer, al menos, una protección básica 
y fundamental para los migrantes climáticos, tanto en el nivel interno como en el internacional.

Como explica Tully (2007), se espera que, por ejemplo, la elevación del nivel del mar fuerce la migración de las poblaciones locales más vulnerables en los asentamientos costeros. Estas personas, que son "víctimas" de la degradación ambiental relacionada con el cambio climático, a priori no encajan en la categoría de refugiados, ni de desplazados internos, puede que algunos sí se adecuaran a la definición de trabajadores migrantes, pero no existe ningún régimen que les garantice protección específica, y así ocurriría con el resto de normativa existente, como se analizó en el apartado anterior. Sin embargo, estas personas deben poder disfrutar de todos sus derechos, como el derecho a la vida, a la alimentación, al agua, a la salud, a la educación, entre otros, gracias a la garantía que supone el sistema de protección de los derechos humanos.

Los motivos principales por los que se debe considerar el derecho internacional de los derechos humanos en relación con las migraciones climáticas son que (1) aseguran un estándar de trato mínimo del cual todos los individuos en el territorio o jurisdicción de un Estado son titulares; (2) cuando las personas se trasladan a otro Estado, proporcionan un estándar de trato mínimo también en el Estado que los recibe; y (3) pueden ser el fundamento al que quienes migran puedan recurrir para solicitar protección en un tercer Estado, basándose en la expansión del principio de "no devolución", aunque dichas solicitudes deberán ser cuidadosamente argumentadas y diseñadas, dadas las complejidades ligadas a la aplicación de este (McAdam, 2011; OHCHR, s. f.).

En este sentido, al menos en teoría, el derecho internacional de los derechos humanos garantiza los derechos básicos de las personas que abandonan sus hogares, debido a los devastadores efectos del cambio climático, pues todas deben disfrutar del conjunto de privilegios civiles, políticos, económicos, sociales, culturales y ambientales establecidos en los diferentes tratados internacionales sobre derechos humanos (McAdam, 2014).

Al mismo tiempo, las normas de derechos humanos establecen ciertas obligaciones que tienen los Estados respecto a los migrantes climáticos. Así, aquellos tienen la obligación de respetar, proteger y garantizar los derechos (sustantivos y procedimentales) de todas las personas, especialmente de grupos vulnerables como los migrantes, en el contexto del cambio climático, así como de asegurar su derecho de no discriminación (CDH, 2016). Además, los Estados deben (i) adoptar ambiciosas medidas de mitigación para prevenir los impactos negativos del cambio climático sobre los derechos humanos; (ii) implantar estrategias de 
adaptación eficaces, con el afán de reducir los riesgos y la vulnerabilidad, al igual que aumentar la capacidad y resiliencia, a fin de prevenir las migraciones climáticas o facilitar su planificación cuando sean necesarias; (iii) asegurar la libertad y seguridad de los migrantes climáticos, así como adoptar acciones para hacer más sencilla una migración con dignidad, en la que el ejercicio de los derechos no se vea restringido; (iv) promover y garantizar el acceso tanto a la información como a la participación de todas las personas, incluyendo los migrantes, en la toma de decisiones relativas al cambio climático; (v) asegurar el derecho de acceso a la justicia y recursos efectivos de los migrantes por los daños generados, debido a los efectos del cambio climático, o medidas de mitigación o adaptación, sobre sus derechos humanos; y, en el nivel internacional, (iv) cooperar para respaldar la seguridad y protección de las poblaciones vulnerables, como los migrantes climáticos, con independencia de donde ellos se encuentren (OHCHR, s. f.). Además, como ya se ha mencionado, el propio Acuerdo de París ha reconocido la importancia de respetar los derechos de las personas migrantes como grupo vulnerable, al señalar que los Estados deben respetar, impulsar y tener en cuenta sus respectivas obligaciones de derechos humanos, cuando adopten medidas para hacer frente al cambio climático (preámbulo).

Con todo, puesto que los derechos humanos se ven afectados en contextos de migraciones climáticas, los Estados deben seguir trabajando para proteger los derechos de las poblaciones afectadas y aumentar esfuerzos, con el propósito de encontrar soluciones en las que sus derechos, necesidades y capacidades sean tomados en cuenta (CDH, 2017).

\subsection{La responsabilidad de los Estados por violaciones a los derechos humanos asociadas al cambio climático}

Dado que la responsabilidad es un elemento central en cualquier sistema legal (Crawford, 2013), se plantea la hipótesis de inculpar a los Estados más contaminantes por sus emisiones históricas de GEI, generadoras del cambio climático que, directa e indirectamente, da lugar a movimientos migratorios. Lo anterior, debido a la falta de adecuada diligencia, en relación con el cumplimiento de sus obligaciones internacionales y, de esta manera, esos entes se ven ante la obligación de cesar los actos ilícitos, o bien, de reparar el daño causado, con base a su responsabilidad internacional. En este sentido, parte de la doctrina considera que las normas secundarias del derecho internacional sobre la responsabilidad de los Estados podrían proporcionar una orientación importante para el desarrollo del régimen internacional sobre el cambio climático, que no parece ser inconsistente con las normas secundarias de aquel. Por lo tanto, nada impide que dichas normas puedan ser aplicables cuando un Estado no cumple con sus compromisos de 
reducir sus emisiones de GEI, en el marco de la CMNUCC o de cualquier otro instrumento internacional en materia de cambio climático (Mayer, 2014). Esto permitiría a las personas que migran por los efectos directos del cambio climático exigir la responsabilidad internacional de los Estados contaminantes.

No obstante, al día de hoy, en lo estipulado por la CMNUCC no se contempla un mecanismo de responsabilidad por el incumplimiento de las obligaciones de los Estados en materia de cambio climático. El papel del derecho internacional de los derechos humanos, por tanto, cobra aún más importancia en este contexto. Actualmente, no parece haber otra vía para las víctimas individuales de daños asociados con el cambio climático, como los migrantes climáticos, si no fuese recurrir a tribunales internacionales en materia de derechos humanos, una vez agotados los recursos internos.

Si bien el presente artículo se enfoca, principalmente, en la responsabilidad de los Estados por violaciones de derechos humanos en el contexto de cambio climático, cabe destacar que también existen las vías legales para hacer efectiva la responsabilidad de las empresas por daños producidos a causa de su contribución al cambio climático. De hecho, dado que las compañías del sector de hidrocarburos y de energía intervienen en gran parte de las emisiones de GEI (Heede, 2014), existen ya precedentes en diversos Estados en los que empresas transnacionales han sido demandadas ante tribunales nacionales.

Por ejemplo, en el 2015, un agricultor peruano demandó a la empresa de energía alemana RWE, por la contribución de sus actividades al cambio climático y, en consecuencia, por incrementar el riesgo del colapso de 2 glaciares en la laguna Palcacocha, poniendo en peligro su vida y seguridad, así como la del resto de la población local, por las posibles inundaciones generadas. A pesar de que el caso fue rechazado en primera instancia, en el 2017, el Tribunal de Hamm, en segunda instancia, determinó su competencia para conocer del asunto y dio paso a la fase de prueba de los hechos controvertidos. Si el fallo determinara la responsabilidad de la empresa RWE (lo que sentaría un precedente histórico), esta tendría que compensar y asumir parte de las medidas de protección de la comunidad afectada (Küper, 2017).

Otro caso por destacar, dada su importancia, es el iniciado contra 47 empresas de combustibles fósiles (incluyendo Shell, ExxonMobil, BP, Repsol, entre otras) ante la Comisión de Derechos Humanos de Filipinas y con el que se exige la responsabilidad de dichas compañías por los daños y vulneraciones a los derechos humanos derivadas del cambio climático. Esto comenzó en el 2015 con una petición presentada ante dicha comisión por representantes de comunidades afectadas, 
sobrevivientes del tifón Haiyan de 2013 y varias ONG, la cual se respaldó en una investigación en la que concluyó que 90 empresas energéticas eran responsables del $63 \%$ de los GEI emitidos entre 1751 y el 2010. Sobre esta base, los peticionarios pretenden establecer la implicación de las empresas, a partir del vínculo causal entre el acto de emitir GEI y los daños o vulneraciones resultantes del cambio climático (UNEP, 2017).

Ahora bien, para desarrollar el análisis de la responsabilidad de los Estados, se toman como punto de partida 2 afirmaciones: por un lado, que unos Estados han contribuido históricamente en mayor medida que otros al cambio climático actual; por otro, que la mayoría de las migraciones climáticas tienen lugar en los países del sur global, los cuales han contribuido en menor medida a este cambio climático.

Al respecto, los principios recogidos, en el 2001, por la Comisión de Derecho Internacional (ILC, por sus siglas en inglés) (ILC, 2001) y reconocidos por la Asamblea General de las Naciones Unidas (ONU, 2002) regulan la responsabilidad internacional de los Estados por actos ilícitos ${ }^{14}$. Con base en ello, cada acto ilícito internacional de un Estado conlleva la responsabilidad internacional de este (Eipiney, 2011). Los Estados tienen la obligación internacional de respetar los derechos humanos establecidos en las convenciones y otros instrumentos, como en el Pacto Internacional de Derechos Económicos, Sociales y Culturales (ONU, 1966b) y en el Pacto Internacional de Derechos Civiles y Políticos (ONU, 1966a). De lo contrario, esto implica la responsabilidad internacional del Estado. Por tanto, cada vez más se reconoce, en la doctrina legal, que las violaciones de derechos humanos a causa de acciones y omisiones de los Estados para hacer frente al cambio climático conllevan la responsabilidad de estos (Wewerinke-Singh, 2018).

Un caso paradigmático en el que por primera vez se intentó determinar la responsabilidad de un Estado por violaciones de derechos humanos asociados al cambio climático es el del pueblo inuit en el Sistema Interamericano de Derecho Humanos (SIDH) (Niehuss, 2005). En el 2005, la Conferencia Circumpolar Inuit, en virtud del derecho contenido en el artículo 44 de la Convención Americana de Derechos Humanos (CADH), presentó una petición ante la Comisión Interamericana de Derechos Humanos (CIDH) contra los Estados Unidos, sobre la base de que la falta de diligencia por parte del Estado para regular la reducción de emisiones de GEI dentro de su jurisdicción amenazaba el disfrute del derecho a mantener la integridad cultural; a un medio ambiente limpio; al uso y disfrute de la propiedad sin interferencias indebidas, y a la vida, la salud, la integridad

14 Los principios establecen, en su artículo 1, que "[t]odo hecho internacionalmente ilícito del Estado genera su responsabilidad internacional". 
física y la seguridad, entre otros reconocidos por la Declaración Universal sobre Derechos Humanos y la CADH.

Estados Unidos es uno de los principales emisores de GEI y el responsable de un alto porcentaje de las emisiones de GEI. Por tanto, los peticionarios instaban a la $\mathrm{CIDH}$ a que se adoptaran medidas paliativas en contra de las violaciones sufridas por el pueblo de los inuit, como resultado del calentamiento global generado por las emisiones de GEI de Estados Unidos. Asimismo, solicitaban que se recomendara a los Estados Unidos la adopción de límites obligatorios a sus emisiones de GEI y la cooperación con la comunidad internacional para evitar interferencias antropogénicas peligrosas en el sistema climático global. Finalmente, pedían que se declarase la obligación del Estado de trabajar con el pueblo de los inuit, con el fin de desarrollar un plan de adaptación a los impactos inevitables del cambio climático y para tener en consideración el impacto de sus emisiones en el Ártico y en los inuit, antes de la aprobación de todas las acciones gubernamentales.

La petición hacía referencia a obligaciones establecidas en la CMNUCC y en los instrumentos del SIDH para evidenciar que el Estado incumplía con sus obligaciones internacionales. No obstante, en el 2006, la petición fue rechazada por la $\mathrm{CIDH}$, debido a la falta de información para determinar si los hechos alegados en tal solicitud constituyeron violaciones de alguno de los derechos protegidos por el SIDH. A pesar de este rechazo, en el 2007, la CIDH concedió al pueblo inuit una audiencia para presentar evidencias que demostraran la conexión entre el cambio climático global y el derecho internacional de los derechos humanos (Gordon, 2007). Las conclusiones de la CIDH sobre esta audiencia fueron que las emisiones de los Estados Unidos deben considerarse una violación de los derechos humanos y recomendó, por tanto, que se adoptaran medidas para poner fin al abuso.

En el 2013, la organización Earthjustice, en nombre del pueblo de Athabaskan que habita en el Ártico, interpuso una segunda petición ante la CIDH, con características similares a las del pueblo inuit. En ella se alegaba que Canadá había fallado en su obligación de regular y limitar las emisiones de carbono negro, consideradas una de las causas del cambio climático. Por ende, se generaban impactos directos en el Ártico que afectaban la salud, la cultura, la propiedad y los medios de subsistencia del pueblo de Athabaskan, violando así derechos contemplados en la Declaración Americana de los Derechos y Deberes del Hombre (Earthjustice, 2013). Esta petición está aún pendiente de resolverse en la CIDH. Si bien cabe la posibilidad de que este caso concluya de la misma manera que la solicitud del pueblo inuit, al menos teóricamente esta tiene mejores probabilidades de no ser rechazada por la Comisión, ya que establece con mayor claridad el nexo causal 
entre la acción del Estado y las violaciones de derechos humanos, a causa del derretimiento del Ártico por las emisiones de carbono negro (McCrimmon, 2016).

En este contexto, si bien se ha llegado a entender que el cambio climático genera consecuencias negativas para el disfrute de los derechos humanos, es menos evidente afirmar si esos efectos pueden llegar a calificarse como violaciones de los derechos humanos, por parte de los Estados contaminantes en sentido jurídico y, de ser así, en qué medida. Las dificultades para sustentar dicha afirmación radican en que a menudo los daños relacionados con el cambio climático no pueden atribuirse claramente a los actos u omisiones de determinados Estados; a que es muy complicado determinar si cierto fenómeno meteorológico está directamente relacionado con el cambio climático, y, por último, a que normalmente se entiende que las violaciones de los derechos humanos ocurren una vez que se ha producido el daño, sin embargo, se tiende a pensar que los efectos adversos del cambio climático son proyecciones de futuro (ACNUDH, 2009).

Ante las dificultades señaladas en el párrafo anterior, existen argumentos suficientes como para, al menos, abrir el debate al respecto. En relación con la complejidad a la hora de atribuir los daños a determinados Estados, generalmente la violación de los derechos humanos se atribuye a los infractores del acto u omisión directamente responsables, por lo que resulta complicado que el cambio climático encaje en esta idea, ya que son muchos los actores que contribuyen a este (Solà, 2012). No obstante, esta atribución no es imposible, pues los datos científicos de emisiones históricas y actuales de GEI demuestran que algunos Estados han contribuido, en mayor medida, al calentamiento global actual, hecho que es reconocido por el derecho internacional, ${ }^{15}$ atribuyendo, de esta manera, una responsabilidad diferenciada a los Estados enriquecidos. Además, la proporción de la responsabilidad de cada Estado puede ser estimada numéricamente, mediante el cálculo de sus emisiones acumuladas a lo largo de la historia (Khan, 2013).

En cuanto a la complicación a la hora de atribuir un fenómeno determinado al cambio climático, se puede tomar como ejemplo el estudio de Hansen, Sato y Ruedy (2012). En él se demuestra que es posible afirmar, con un alto grado de confianza, que ciertas anomalías extremas, como las ocurridas en Moscú en el 2010, al igual que en Texas y Oklahoma en el 2011, fueron consecuencia del calentamiento global, porque la probabilidad de que sucedieran en ausencia de este era extraordinariamente limitada. Otro estudio muestra que la disminución de las precipitaciones, durante la estación de cultivo en el este y sur de África, está relacionada

15 El preámbulo de la CMNUCC, por ejemplo, incluye que "(...) tanto históricamente como en la actualidad, la mayor parte de las emisiones de gases de efecto invernadero del mundo han tenido su origen en los países desarrollados" (ONU, 1992). 
con el calentamiento antropogénico en el océano Índico (Funk et al., 2008). De la misma forma, otra investigación reveló la influencia del cambio climático en la intensidad del tifón Haiyan que arrasó Filipinas en el 2013 (Trenberth et. al, 2015). Así, a pesar de la escasa y relativa lentitud de la evidencia científica, tampoco es imposible demostrar que ciertos eventos son debidos al cambio climático.

Finalmente, en relación con la dificultad sobre los efectos del cambio climático como proyecciones futuras, cabe destacar que ya se ha constatado que las temperaturas han aumentado, especialmente las de los océanos, las precipitaciones se han incrementado en las latitudes medias del hemisferio norte, el océano se ha acidificado, las masas de hielo de Groenlandia y del Ártico junto con los glaciares se han ido derritiendo y la media de nivel del mar se ha elevado (IPCC, 2014).

Otro de los planteamientos para hacer efectiva la responsabilidad internacional de los Estados por violaciones de derechos humanos asociadas al cambio climático es que el derecho internacional de los derechos humanos generalmente crea obligaciones de los Estados respecto a los individuos bajo su jurisdicción, por lo cual, a menudo, quedan difusos los deberes de aquellos sobre las personas y situaciones más allá de su jurisdicción (Brown, 2015). En el caso de los migrantes climáticos, una persona que se ve forzada a trasladarse por motivos climáticos podría exigir la responsabilidad del Estado del que migra, pero queda menos claro si se podría utilizar el marco de los derechos humanos en el contexto del compromiso internacional de los Estados, para interponer un recurso ante un Estado contaminante extranjero.

En la reciente Opinión Consultiva de la Corte Interamericana de Derechos Humanos sobre derechos humanos y medio ambiente, se clarifican las obligaciones extraterritoriales de los Estados para prevenir daños ambientales que afecten los derechos humanos. En esta, se establece que la jurisdicción de los Estados, en cuanto a protección de los derechos humanos de las personas bajo la $\mathrm{CADH}$, no se limita a su espacio territorial. El término jurisdicción en la CADH es más extenso que el territorio de un Estado e incluye situaciones que rebasan sus límites territoriales. Por tanto, los Estados se encuentran obligados a respetar y garantizar los derechos humanos de todas las personas bajo su jurisdicción, aunque no estén dentro de su territorio. Esto implica que deben velar porque este último no sea utilizado, de modo que se pueda causar un daño significativo al medio ambiente de otros Estados o de zonas fuera de los límites de su territorio. No obstante, para determinar la responsabilidad de un Estado por violaciones de derechos humanos de carácter extraterritorial debe existir una relación de causalidad entre el daño ocasionado y la acción u omisión del Estado de origen frente a actividades en su territorio, así como bajo su jurisdicción o control. Esto nos lleva de nuevo al punto 
de tener que demostrar que las emisiones de GEI pertenecientes a cierto Estado afectan el disfrute de los derechos humanos de las personas en un tercer Estado (Corte IDH, 2018).

De acuerdo con lo señalado anteriormente, se constata que los impactos del cambio climático afectan el disfrute de los derechos humanos de muchas personas y, por ende, generan violaciones a normas internacionales, lo que resulta cada vez más evidente en el caso de los migrantes climáticos (Brown, 2015). Entonces, si las consecuencias adversas del cambio climático suponen una violación a las reglas internacionales de los derechos humanos, los Estados, en cumplimiento con sus obligaciones internacionales, tienen el deber de adoptar normas jurídicas para prevenir, minimizar y reparar los daños causados. Asimismo, un enfoque basado en los derechos humanos debe formar parte de cualquier respuesta política que intente abordar los diferentes tipos de migración climática (Boncour y Burson, 2010).

Cabe plantearse, entonces, que corresponde a los Estados enriquecidos y más contaminantes responsabilizarse de sus acciones pasadas y actuales, incluso ante personas que no residen en su jurisdicción, con base en razones de justicia intrae intergeneracional. No sería solamente necesario determinar que un Estado en particular es responsable de un daño, sino habría que identificar qué principio o norma ha sido quebrantada. Con frecuencia, el cambio climático conlleva violaciones de derechos humanos tan graves que se justifica que las obligaciones y responsabilidades sean concebidas no solo en el nivel interno, también en el supranacional (Ruppel y Wyk, 2013). Así, debería ser obligación de los Estados enriquecidos (como Australia o Nueva Zelanda) cercanos a los pequeños Estados insulares (como Kiribati o Tuvalu) colaborar en la reubicación de los habitantes afectados hacia su territorio, fundamentando la obligación de proteger el derecho a la vida (Tully, 2007).

El principio de la responsabilidad solidaria, que a menudo se encuentra en los sistemas de responsabilidad civil por daños, podría emplearse, además, para justificar la obligación de admitir a un migrante climático en un Estado determinado (anfitrión), a pesar del hecho de que hayan sido muchos los Estados contribuidores de la causa de su migración, es decir, el cambio climático. Cuanto mayor haya sido la contribución del Estado anfitrión al total de emisiones de GEI, más sería el peso del argumento del migrante climático para poder permanecer en ese Estado (Scott, 2014).

Finalmente, a pesar de las limitaciones del empleo de las normas internacionales de protección de los derechos humanos para responsabilizar a los Estados que contribuyen de manera sustancial al cambio climático (limitaciones territoriales 
de las obligaciones, escasa capacidad de represión, etc.), en la actualidad se están investigando las posibles vías para inculpar a dichos Estados por daños y riesgos tan graves como los que sufren los migrantes climáticos. Un ejemplo es que en marzo de 2015 se adoptaron los "Principios de Oslo sobre Cambio Climático", que incluyen las obligaciones jurídicas básicas de los Estados y las empresas para responder urgente y efectivamente al cambio climático, protegiendo los derechos humanos de las personas y evitando las nefastas consecuencias de este (Expert Group on Global Climate Obligations, 2015; Nagra, 2017).

En suma, que un tribunal internacional en materia de derechos humanos considere que los impactos del cambio climático generados por determinados Estados violan los derechos de los migrantes climáticos, traería consigo importantes avances; por ejemplo, que aquellas personas cuyos derechos hayan sido violados logren una compensación. De esta manera, el derecho internacional de los derechos humanos impondría a los Estados el deber de prevenir la migración forzada de las personas por el cambio climático y la responsabilidad de ayudar en las tareas de adaptación; a la vez, pagar por los costes de las reubicaciones y compensar por los daños causados. Asimismo, otra medida de reparación del perjuicio causado podría consistir en llegar a ser aceptados en esos Estados con permiso de residencia permanente, o temporal, si la opción de regresar a sus hogares siguiera siendo posible (Brown, 2015). En definitiva, al menos por el momento, el acceso a los tribunales internacionales en materia de derechos humanos para hacer efectiva la responsabilidad de los Estados se convierte en una forma de superar la situación de desprotección jurídica de los migrantes climáticos y de generar presión a los Estados, con el afán de que reduzcan sus emisiones de GEI o de que provean un mayor financiamiento que compense los daños y riesgos sufridos por las personas que huyen de los devastadores efectos del cambio climático.

\section{CONCLUSIONES}

Las migraciones climáticas son ya una realidad y, por tanto, brindar respuestas al sinnúmero de desafíos presentes y futuros que ellas conllevan es cada vez más urgente. La falta de protección de las personas que huyen de sus territorios a causa del cambio climático ha quedado en evidencia, por lo que el debate de vías alternativas que posibiliten la protección de sus derechos es más que oportuna.

Como se ha señalado en este trabajo, el derecho internacional de los derechos humanos constituye una garantía de mínimos para la protección de los migrantes climáticos. Este puede ser empleado, al menos en parte, para exigir la responsabilidad de las naciones más contaminantes, en relación con proteger efectivamente a estas personas, así como para presionar a los Gobiernos a que reduzcan sus 
emisiones de GEI y provean un mayor financiamiento que compense los daños y riesgos sufridos por los migrantes climáticos.

Por otro lado, acudir al derecho internacional de los derechos humanos no resulta suficiente para acabar con la (des)protección jurídica en la que se encuentran los migrantes climáticos. A pesar de su importancia y las alternativas que brinda, el régimen internacional de los derechos humanos posee ciertas limitaciones, al no ofrecer respuestas claras, por ejemplo, sobre la admisión en un Estado extranjero o el estatuto que deben recibir los migrantes climáticos. Así, resulta necesaria la adaptación de instrumentos del derecho internacional de las migraciones a la realidad de las migraciones climáticas. Además, se deben generar avances significativos en el régimen internacional del cambio climático. El Acuerdo de París supone un paso importante, pero la lentitud de los procesos y la tímida ambición de las acciones evidencian la necesidad de promover propuestas holísticas para la protección efectiva de los migrantes climáticos. Asimismo, la adopción de un tratado universal vinculante ad hoc, aunque sea a más largo plazo y de acuerdos tanto bilaterales como regionales podría mejorar la situación de quienes migran por motivos climáticos, garantizando la protección de sus derechos básicos. La atención y el debate de este, al igual que otro tipo de propuestas son necesarios ante la actual crisis climática que está poniendo en evidencia, cada vez más, las desigualdades e injusticias a las que se enfrentan quienes migran por motivos climáticos.

\section{Referencias}

Acevedo, P. (2014). Desplazados ambientales, globalización y cambio climático: mirada desde los derechos humanos y de los pueblos indígenas. Temuco, Chile: Observatorio Ciudadano.

ACNUDH. (2018). International Convention on the Protection of the Rights of All Migrant Workers and Members of their Families. Status Of Ratification. Recuperado de http://indicators.ohchr.org/

ACNUDH. (2009). Informe de la Oficina del Alto Comisionado de las Naciones Unidas para los Derechos Humanos sobre la relación entre el cambio climático y los derechos humanos. A/HCR/10/61. Nueva York: Alto Comisionado de las Naciones Unidas para los Derechos Humanos.

ACNUR. (2008). Cambio climático, desastres naturales y desplazamiento humano: la perspectiva del ACNUR. Actualización. Ginebra: ACNUR. Recuperado de www.unhcr.org/497891022.pdf

AGNU. (2005). Documento Final de la Cumbre Mundial 2005. Doc A/RES/60/1 24 de octubre de 2005.

Barnett, J. (2001). Adapting to Climate Change in Pacific Island Countries: The Problem of Uncertainty. World Development, 29(6), 977-993. https://doi.org/10.1016/S0305-750X(01)00022-5 
Behrman, S. y Kent. A. (Eds.) (2018). 'Climate Refugees' Beyond the Legal Impasse? Londres: Routledge. https://doi.org/10.4324/9781315109619

Biermann, F. y Boas, I. (2008). Protecting Climate Refugees: The Case for a Global Protocol. Environment: Science and Policy for Sustainable Development, 50(6), 8-17. https://doi. org/10.3200/ENVT.50.3.6-17

Biermann, F. y Boas, I. (2010). The Case of Protecting Climate Refugees. En F. Biermann, P. Pattberg y F. Zell (eds.), Global Climate Governance Beyond 2012: Architecture, Agency and Adaptation (pp. 255-269). Cambridge: Cambridge University Press. https://doi.org/10.1017/ CBO9781139107150.020

Boncour, P. y Burson, B. (2010). Climate Change and Migration in the South Pacific Region: Policy Perspectives. En B. Burson (ed.), Climate Change and Migration. South Pacific Perspectives (pp. 5 - 28). Wellington: Institute of Policy Studies. https://doi.org/10.26686/pq.v5i4.4312

Bronen, R. (2010). Forced Migration of Alaskan Indigenous Communities Due to Climate Change. En T. Afifi y J. Jäger (eds.), Environment, Forced Migration and Social Vulnerability (pp. 87 - 98). Berlin: Springer. https://doi.org/10.1007/978-3-642-12416-7_7

Brown, D. A. (2015). Climate Change Refugees: Law, Human Rights and Ethics. En L. Westra, J. Satvinder y T. Scovazzi (eds.), Towards a Refugee Oriented Right of Asylum (pp. 43 - 63). Reino Unido: Ashgate.

Brown, L. (1976). Twenty-Two Dimensions of the Population Problem. Recuperado de http://files. eric.ed.gov/fulltext/ED128282.pdf https://doi.org/10.2307/1965104

Burkett, M. (2011). The Nation Ex-Situ: On climate change, deterritorialized nationhood and the post-climate era. Climate Law, 2, 345-374. https://doi.org/10.1163/CL-2011-040

Castillo, J. (2011). Migraciones Ambientales: Huyendo de la Crisis Ecológica en el siglo XXI. Barcelona: Virus editorial.

CDH. (2012). Informe del Relator Especial sobre los derechos humanos de los migrantes. Doc. A/67/299. 13 de agosto de 2012.

CDH. (2016). Informe del Relator Especial sobre la cuestión de las obligaciones de derechos humanos relacionadas con el disfrute de un medio ambiente sin riesgos, limpio, saludable y sostenible. Doc. A/HRC/31/52. 1 de febrero de 2016.

CDH. (2017). Informe de la Oficina del Alto Comisionado de las Naciones Unidas para los Derechos Humanos. Doc. A/HRC/35/13. 4 de mayo de 2017.

Celis, R. y Aierdi, X. (2015). ¿Migración o desplazamiento forzado? Las causas de los movimientos de población a debate. Cuadernos Deusto de Derechos Humanos 81. Bilbao: Universidad de Deusto. 
Clark, B. (26 de enero de 2016). El segundo lago más grande de Bolivia se secó ¿Hay salvación? National Geographic en Español. Recuperado de www.ngenespanol.com/naturaleza/ ecosistemas/16/01/26/sequia-lago-bolivia-cambio-climatico-poopo-muerte/

CMNUCC. (2010). Informe de la Conferencia de las Partes sobre su 15. período de sesiones, celebrado en Copenhague del 7 al 19 de diciembre de 2009. Adición. Segunda parte: medidas adoptadas por la Conferencia de las Partes en su 15.ํㅜ período de sesiones. Doc. FCCC/CP/2009/11/Add.1 de 30 de marzo de 2010.

CMNUCC. (2015). Informe de la Conferencia de las Partes 21 período de sesiones. París, 30 de noviembre a 11 de diciembre de 2015. Doc. FCCC/CP/2015/L.9.

CMNUCC. (2017). Task Force on Displacement. Recuperado de http://unfccc.int/adaptation/ groups_committees/loss_and_damage_executive_committee/items/9978.php

Cooper, J. (1998). Environmental Refugees: Metting the Requierements of the Refugee Definition. N.Y.U. Environmental Law Journal, 1, 480.

Corte IDH. (2018). Medio ambiente y derechos humanos (obligaciones estatales en relación con el medio ambiente en el marco de la protección y garantía de los derechos a la vida y a la integridad personal - interpretación y alcance de los artículos 4.1 y 5.1, en relación con los artículos 1.1 y 2 de la Convención Americana sobre Derechos Humanos). Opinión Consultiva OC-23/17 de 15 de noviembre de 2017. Serie A no. 23.

Crawford, J. (2013). State Responsibility: The General Part. Cambridge: CUP. https://doi. org/10.1017/CBO9781139033060

Displacement Solutions. (2013). Los principios Península sobre el Desplazamiento Climático dentro de los Estados. Recuperado de http://displacementsolutions.org/wp-content/uploads/ Peninsula-Principles-Spanish.pdf

Displacement Solutions (2016). An Overview on the Relocation of Guna Indigenous Communities in Gunayala, Panama - Mission Report. Recuperado de http://displacementsolutions. org/wp-content/uploads/2017/01/Gunayala-Planned-Relocation-Jan-2017.pdf

Dun, O. y Gemenne, F. (2008). Defining «environmental migration». Forced Migration Review, $31,10-11$.

Duong, T. (2010). When Islands Drown: the Plight of «Climate Change Refugees» and Recourse to International Human Rights Law. University of Pennsylvania Journal of International Law, 31(6), 1239-1266.

Earthjustice. (2013). Petition to the Inter-American Commission on Human Rights Seeking Relief from Violations of the Rights of Arctic Athabaskan Peoples Resulting from Rapid Arctic Warming 
and Melting Caused by Emissions of Black Carbon by Canada. Recuperado de https://earthjustice.org/sites/default/files/AAC_PETITION_13-04-23a.pdf

Eipiney, A. (2011). «Environmental refugees»: aspects of international state responsibility. En E. Piguet, A. Pécoud y P. De Guchteneire (eds.), Migration and Climate Change (pp. 388 - 414). Nueva York: UNESCO Publishing.

Entzinger, H. y Scholten, P. (2016). Adapting to Climate Change through Migration a case study of the Vietnamese Mekong River Delta. Ginebra: OIM.

Expert Group on Global Climate Obligations. (2015). Oslo Principles on Global Climate Obligations. Recuperado de http://globaljustice.macmillan.yale.edu/sites/default/files/files/ OsloPrinciples.pdf

Fatima, R., Jawadurovna, A. y Coelho S. (2014). Human Rights, Climate Change, Environmental Degradation and Migration: a New Paradigm. Issue in Brief 8. Bangkok: IOM Regional Office for Asia and the Pacific.

Felipe, B. (2016). Las migraciones climáticas: Retos y propuestas desde el Derecho internacional. (Tesis doctoral inédita). Universidad Rovira i Virgili, Tarragona.

Felipe, B. (2018). Moving Beyond the Shortcomings of International Law: a Proposal for the Legal Protection of Climate Migrants. En S. Behrman y A. Kent, A. (eds.), 'Climate Refugees': Beyond the Legal Impasse (pp. 214 - 230). Oxford: Routledge.

Felipe, B. y Salles, F. (2015). Las migraciones inducidas por el Cambio Climático. La situación en Alaska, ¿refugiados ambientales? En S. Borrás y D. Annoni (coord.), Retos Internacionales de la Protección de los Derechos Humanos y el Medio Ambiente. Florianápolis, Brasil: Gedai.

Funk, C., Dettinger, M. D., Michaelsen, J. C., Verdin, J. P., Brown, M. E., Barlow, M. y Hoell, A. (2008). Warming of the Indian Ocean threatens eastern and southern African food security but could be mitigated by agricultural development. Proceedings of the National Academy of Sciences of the United States of America, 105(32), 11081-11086. https://doi. org/10.1073/pnas.0708196105

Gagain, M. (2012). Climate Change, Sea Level Rise, and Artificial Islands: Saving the Maldives' Statehood and Maritime Claims through the Constitution of the Oceans. Colorado Journal of International Environmental Law and Policy, 23, 79-101.

Gemenne, F. (2011). Why the numbers don't add up: A review of estimates and predictions of people displaced by environmental changes. Global Environmental Change, 21(SUPPL. 1), 41-49. https://doi.org/10.1016/j.gloenvcha.2011.09.005 
Gogarty, B. (2011). ClimateChange Displacement: Current Legal Solutions to Future Global Problems. Journal of Law, Information $\mathcal{E}$ Science, 21(1), 167 - 188. https://doi.org/10.2139/ ssrn.1976899

Godínez, R. (2006). Cambio climático y Derechos Humanos. En J. U.Carmona y J. M. Hori (eds.), Derechos Humanos y Medio Ambiente. México: Universidad Nacional Autónoma de México, Instituto de Investigaciones Jurídicas, Secretaría de Medio Ambiente y Recursos Naturales.

Gordon, J. (2007). Inter-American Commission On Human Rights To Hold Hearing After Rejecting Inuit Climate Change Petition. Sustainable Development Law Ë Policy, 7(2), 55.

Hales, S., Kovats, S., Lloyd, S. y Campbell-Lendrum, D. (Eds). (2014). Quantitative risk assessment of the effects of climate change on selected causes of death, 2030s and 2050s. Ginebra: World Health Organization.

Hamza, M., Koch, I. y Plewa, M. (2017). El desplazamiento inducido por desastres en el Caribe y en el Pacífico. Forced Migration Review, 56, 62-65.

Hansen, J., Sato, M. y Ruedy, R. (2012). Perception of climate change. Proceedings of the National Academy of Sciences, 109(37), E2415-E2423. https://doi.org/10.1073/pnas.1205276109

Heede, R. (2014). Tracing anthropogenic carbon dioxide and methane emissions to fossil fuel and cement producers, 1854-2010. Climatic Change, 122(1-2), 229-241. https://doi. org/10.1007/s10584-013-0986-y

Hodkinson, D. (2011). A Convention for Persons Displaced by Climate Change. Recuperado de www.ccdpconvention.com/documents/CCDP Convention FAQs.pdf

Horne, B. (2006). Internship Paper: What is the Status of «Environmental Refugees» Under International and Australian Law? Recuperado de www.cla.asn.au/Articles/060203BrookeHome.pdf

IASC. (2008). Human Rights and Natural Disasters. Operational Guidelines and Field Manual on Human Rights Protection in Situations of Natural Disasters. Washington DC: IASC.

IDMC. (2015). Global Estimates 2015. People displaced by disasters. Ginebra: IDMC.

IDMC. (2017). Global Report on Internal Displacement. Ginebra: IDMC.

IDMC. (2018). Global Report on Internal Displacement. Ginebra: IDMC.

ILC. (2001). Draft Articles on Responsibility of States for Internationally Wrongful Acts. Yearbook of the International Law Commission, 2(2), 30-77.

IPCC. (2014). Cambio climático 2014. Impactos, adaptación y vulnerabilidad. Resumen para responsables de políticas. Resumen para responsables de políticas. Contribución del Grupo 
de trabajo II al Quinto Informe de Evaluación del Grupo Intergubernamental de Expertos sobre el Cambio Climático. Ginebra: Organización Meteorológica Mundial.

Jamieson, D. (2011). The Nature of the Problem. En J. Dryzek, R. Norgaard y D. Schlosberg (eds.), The Oxford Handbook on Climate Change and Society (pp. 38 - 54). Oxford: Oxford University Press.

Khan, H. (2013). Legal and Policy Responses to Loss and Damage Associated with Climate Change. En O. Ruppel, C. Roschmann y K. Ruppel-Schlichting (eds.), Climate Change: International law and Global Governance. Volume II: Policy, Diplomacy and Governance in a Changing Environment (pp. 843-875). Alemania: Nomos.

Küper, S. (2017). Historic breakthrough with global impact in "climate lawsuit". Recuperado de https://germanwatch.org/en/14795

Mayer, B. (2014). State Responsibility and Climate Change Governance: A Light through the Storm. Chinese Journal of International Law, 13(3), 539-575. https://doi.org/10.1093/ chinesejil/jmu030

McAdam, J. (2011). Refusing «refugee» in the Pacific: (de)constructing climate-induced displacement in international law. En E. Piguet, A. Pécoud, y P. Guchteneire (eds.), Migration and Climate Change (pp. 102 - 137). Cambridge: Cambridge University Press.

McAdam, J. (2014). Human Rights and Forced Migration. En E. Fiddian-Qasmiyeh, G. Loescher, K. Long y N. Sigona (eds.), The Oxford Handbook of Refugees and Forced Migration Studies (pp. 203-2015). Oxford: Oxford University Press.

McCrimmon, D. (2016). The Athabaskan Petition to the Inter-American Human Rights Commission: using human rights to respond to climate change. The Polar Journal, 6(2), 398-416. https://doi.org/10.1080/2154896X.2016.1241484

MICIC. (2016). Migrants in Countries in Crisis (MICIC) Initiative. Recuperado de https://micicinitiative.iom.int/sites/default/files/document/micic_guidelines_english_web_13_09_2016. pdf $\#$ page $=21$

Nagra, S. (2017). The Oslo Principles and Climate Change Displacement: Missed Opportunity or Misplaced Expectations? Carbon EG Climate Law Review, 11(2), 120-135. https://doi. org/10.21552/cclr/2017/2/8

Nansen Initiative. (2014). Outcome Report. Natural Hazards, Climate Change, and Cross-Border Displacement in the Grater Horn of Africa: Protecting People on the Move. Nairobi: Nansen Initiative.

Nansen Initiative. (2015). The Nansen Initiative. Global Consultation. Conference Report. Ginebra, 12- 13 de octubre de 2015. 
Niehuss, J. (2005). Inuit Circumpolar Conference v. Bush Administration: Why the Arctic Peoples Claim the United States' Role in Climate Change has violated their Fundamental Human Rights and Threatens their Very Existence. Sustainable Development Law $\mathcal{E}$ Policy, 5(2), 66-67.

OHCHR (s. f.). Key Messages on Human Rights, Climate Change, and Migration. Recuperado de www.ohchr.org/Documents/Issues/ClimateChange/Key_Messages_HR_CC_Migration.pdf.

OIM. (2014). The State of Environmental Migration 2014. A review of 2013. Ginebra: OIM y Science Po.

OMS. (2012). Atlas de la Salud y del Clima. Suiza: OMS.

OMS. (2016). Género, cambio climático y salud. Suiza: OMS.

ONU. (1951). Convención sobre el Estatuto de los Refugiados. Serie de Tratados de las Naciones Unidas, vol. 189, no. 545, p. 137.

ONU. (1954). Convención sobre el Estatuto de los Apátridas. Serie de Tratados de las Naciones Unidas, vol. 360, no. 5158, p. 117.

ONU. (1961). Convención sobre la Reducción los Casos de Apatridia. Serie de Tratados de las Naciones Unidas, vol. 989, p. 175.

ONU. (1966a). Pacto Internacional de Derechos Civiles y Políticos. Serie de Tratados de las Naciones Unidas, vol. 999, no. 14668, p. 171.

ONU. (1966b). Pacto Internacional de Derechos Económicos, Sociales y Culturales. Serie de Tratados de las Naciones Unidas, vol. 993, no. 14531, p. 3.

ONU. (1967). Protocolo sobre el Estatuto de los Refugiados. Serie de Tratados de las Naciones Unidas, vol. 606, no. 8791, p. 267.

ONU. (1984). Declaración de Cartagena sobre los Refugiados. Recuperado de www.unhcr.org/ about-us/background/45dc19084/cartagena-declaration-refugees-adopted-colloquium-international-protection.html

ONU. (1990). Convención Internacional sobre la Protección de los Derechos de Todos los Trabajadores Migratorios y de sus Familiares. Serie de Tratados de las Naciones Unidas, vol. 2220 , no. 39481 , p. 3.

ONU. (1992). Convención Marco de las Naciones Unidas sobre el Cambio Climático. Serie de Tratados de las Naciones Unidas, vol. 1771, no. 30822, p. 107. 
ONU. (1997). Protocolo de Kyoto a la Convención Marco de las Naciones Unidas sobre Cambio Climático. Serie de Tratados de las Naciones Unidas, vol. 2303, no. 30822, p. 162.

ONU. (2002). Responsabilidad del Estado por Hechos Internacionalmente Ilícitos. Resolución aprobada por la Asamblea General A/Res/56/83.

ONU. (2015). Transformar nuestro mundo: la Agenda 2030 para el Desarrollo Sostenible. Resolución aprobada por la Asamblea General A/RES/70/1.

ONU. (2016). Declaración de Nueva York para los Refugiados y los Migrantes. Resolución aprobada por la Asamblea General A/71/L.1.

OUA. (1969). Convención de la Organización de la Unión Africana por la que se regulan Aspectos Específicos de Problemas de los Refugiados en África. Serie de Tratados de las Naciones Unidas, vol. 1001, no. 14689, p. 45.

OUA. (2009). Convención de la Unión Africana para la Protección y la Asistencia de los Desplazados Internos en África (Convención de Kampala). Serie de Tratados de las Naciones Unidas, vol. 3013.

OXFAM. (2009). Suffering the Science: Climate change, people and poverty. Recuperado de www. oxfam.org/sites/www.oxfam.org/files/file_attachments/bp130-suffering-the-science_14.pdf

PDD. (s. f.). The Platform. Recuperado de http://disasterdisplacement.org/about-us.

Pender, J. (2008). Community-led adaptation in Bangladesh. Forced Migration Review, 31, 54-55.

Pires, E. (2013). Climate Change, Disasters and Migration: Current Challenges to International Law. En O. Ruppel, C. Roschmann y K. Ruppel-Schlichting (eds.), Climate Change: International Law and Global Governance (pp. 739-760). Baden-Baden: Nomos. https://doi. org/10.5771/9783845242774_739

Pires, E., Lyra, L., Salles, F. y Abreu, C. (2016). Environmental migration in Brazil: Current contact and systemic challenges. Migration, Environment and Climate Change: Policy Brief Series, 2(5), 1-8.

Prieur, M. (2011). Draft Convention on the International Status of Environmentally-Displaced Persons. The Urban Lawyer, 43(1), 247-257.

Priotto, G. (2017). Migraciones, ambiente y cambio climático. Estudios de Caso en América del Sur. Cuadernos Migratorios 8. Buenos Aires: OIM.

Rezaul, M. (2017). Climate Change, Natural Disasters and Socioeconomic Livelihood Vulnerabilities: Migration Decision Among the Char Land People in Bangladesh. Social Indicators Research, (Online First),1-19. 
Ruppel, O. y Wyk, S. (2013). Climate-change-induced Movement of Persons in Africa: Human Rights Responses to Aspects of Human Security. En O. C. Ruppel, C. Roschmann y K. Ruppel-Schlichting (eds.), Climate Change: International Law and Global Governance (pp. 799-828). Alemania: Nomos. https://doi.org/10.5771/9783845242774_799

Sarshar, M. (2011). Environmental Refugees. Selected Works. Recuperado de https://works. bepress.com/mubashshir/27/

Scott, M. (2014). Natural Disasters, Climate Change and Non-Refoulement: What Scope for Resisting Expulsion under Articles 3 and 8 of the European Convention on Human Rights? International Journal of Refugee Law, 26(3), 404-432. https://doi.org/10.1093/ijrl/eeu036

Sherbinin, A. (2014). Climate change hotspots mapping: What have we learned? Climatic Change, 123(1), 23-37. https://doi.org/10.1007/s10584-013-0900-7

Solà, O. (2012). Desplazados medioambientales. Una nueva realidad. Cuadernos Deusto de Derechos Humanos 66. Bilbao.

Storlazzi, C., Gingerich, S., Dongeren, A., Cheriton, O., Swarzenski, P., Quataert, E., Clifford, E., Voss, I., Field, W., Annamalai, H., Piniak, I.G., McCall, R. (2018). Most atolls will be uninhabitable by the mid-21st century because of sea-level rise exacerbating wave-driven flooding. Science Advances, 4(4), eaap9741. https://doi.org/10.1126/sciadv.aap9741

The Government Office for Science. (2011). Foresight: Migration and Global Environmental Change. Final Project Report. Londres: The Government Office for Science.

Trenberth, K., Fasullo, J. y Shepherd T. (2015). Attribution of climate extreme events. Nature Climate Change, 5, 725-730. https://doi.org/10.1038/nclimate2657

Tully, S. (2007). The Contribution of Human Rights as an Additional Perspective on Climate Change Impacts within the Pacific. New Zealand Journal of Public and International Law, 5, 169-202.

Türk, V. y Dowd, R. (2014). Protection Gaps. En E. Fiddian-Qasmiyeh, G. Loescher, K. Long y N. Sigona (eds.), The Oxford Handbook of Refugee and Forced Migration Studies (pp. 278301). Oxford: Oxford University Press.

UK Climate Change and Migration Coalition. (2015). Paris - Displacement and Migration. What happens next? Recuperado de http://climatemigration.org.uk/ alex_randall-paris-displacement-and-migration-what-happens-next/

UNESCO (2005). La Convención de las Naciones Unidas sobre los Derechos de los Migrantes. Kit informativo. Francia: UNESCO. 
UNEP. (2017). The Status of Climate Change Litigation - A Global Review. Recuperado de http://wedocs.unep.org/bitstream/handle/20.500.11822/20767/climate-change-litigation. pdf? sequence $=1$ \& is Allowed $=y$.

Warner, K., Sherbinin, A. y Chai-Onn, T. (2009). In search of shelter. Mapping the Effects of Climate Change on Human Migration and Displacement. Recuperado de http://ciesin.columbia. edu/documents/clim-migr-report-june09_final.pdf

Wewerinke-Singh, M. (2018). State Responsibility for Human Rights Violations Associated with Climate Change. En S. Duyck, S. Jodoin y A. Johl, (eds.), Handbook of Human Rights and Climate Governance (pp. 75-89). Nueva York: Routdlege. https://doi. org/10.4324/9781315312576-6

Recibido: $14 / 6 / 2018$

Aceptado: 2/5/2019 